\title{
EARING CONTROL AND DEFORMATION PROCESSING OF ALUMINIUM ALLOYS
}

\author{
Ph. LEQUEU
}

Centre de Recherches de Voreppe S.A., Pechiney, BP 27, 38340 Voreppe, France

\begin{abstract}
The production of ear free aluminium flat rolled products highly depends on the ability to balance the deformation and recrystallization textures at the final gauge. A model based on the concept of earing diagram is proposed, which enables the process-texture-earing relationships to be assessed in a fairly simple way. It is shown that such a predictive tool can be used for the definition of optimized fabrication schedules leading to ear free material. Such earing control is achieved by a control of both the microstructural evolution as well as the position of the recrystallization steps along the complete fabrication sequence.
\end{abstract}

\section{I - INTRODUCTION}

Packaging is one of the most challenging market for the aluminium producers in the 90 's. The growth of aluminium rigid container sheet aimed at food or beverage cans has been phenomenal over the last two decades and future projections all include ambitious downgauging programs. This need for thinner gauges will be granted only at the expense of a new strength / formability compromise, i.e. through the development of higher strength alloys with optimized forming performance.

Earing is part of this compromise as long as downgauging with the classical existing fabrication schedules leads to increased $45^{\circ}$ ears after deep drawing. Extensive earing can lead to a non-desired increase in blank diameters as well as in ironing tear-offs due to local thickness heterogeneities.

Texture has been long recognized to be the major source of plastic anisotropy. A rolling texture in F.C.C. metals and alloys produces $45^{\circ}$ earing whereas recrystallization texture produces symetrical $0 / 90^{\circ}$ ears. The production of ear free materials depends thus on the ability of balancing these two types of textures. This can be done by a control of the various steps of the complete fabrication schedule, i.e. casting, pre-heating, hot rolling, cold rolling and, when necessary, interannealing.

The aim of this paper is to introduce a practical method aimed at controlling earing through a control of the microstructure and thermomechanical processing of flat rolled products. 


\section{II - EARING : DEFINITION, AND RELATION TO TEXTURE}

When deep drawn, a circular blank gives rise to a cup showing alternative peaks and troughs, the position and size of which strongly depend on the nature of the material and of the deep-drawing conditions : 4, 6 or 8 years are commonly found in aluminium alloys, depending on their fabrication schedule.

The relative behaviours of sheets can be compared by means of the earing percentage. This can be defined as :

$$
\mathrm{E} \%=(\mathrm{H} \text { peaks }-\mathrm{H} \text { troughs }) / \mathrm{H}
$$

where $\mathrm{H}$ peaks, $\mathrm{H}$ troughs and $\mathrm{H}$ are respectively the average height of peaks, troughs and cup.

The relationship between texture and earing has long been demonstrated on a qualitative point of view : $45^{\circ}$ and $0 / 90^{\circ}$ earing are associated respectively withrolling and recrystallization textures. Much effort has been dedicated to the determination of the texture/earing relationship. Empirical methods can be used where the earing percentage is defined as a linear function of some texture data [1-2]. More sophisticated methods are also reported, based (i) on the early work by Tucker [3-4] taking account for shear on activated slip systems or (ii) on solving the equilibrium stress equations in the drawn blank coupled with a Taylor-Bishop and Hill plasticity model [5-6]. All these models predict fairly well the earing tendency when rolling or recrystallization textures are introduced. However, they often fail in predicting complicated 6 or 8 ears profiles corresponding to mixed textures and in calculating accurately the earing percentage. In the present work, an empirical relationship between texture and earing has been used

$$
\mathrm{E} \%=\mathbf{a}(2.7 \mathrm{C}-\mathrm{R})
$$

where $C$ and $R$ are respectively the intensity of the cube and deformation textures measured on a (220) pole figure, and " $\mathrm{a}$ " is a constant depending on the conditions for the texture determination. Figure 1 illustrates the method used for the determination of the $C$ and $\mathbf{R}$ intensities as well as the comparison between calculated and measured earing on various samples of Commercial Purity (C.P.) aluminium. Eq. 1 is very similar to that reported in ref. [2].

\section{III - EARING CONTROL : THE USE OF EARING DIAGRAMS}

The fabrication schedule of aluminium alloys involves a series of deformation and recrystallization processes. Each of these steps is associated with microstructural and textural evolutions so that earing control can be achieved when controling the following complicated relationships :

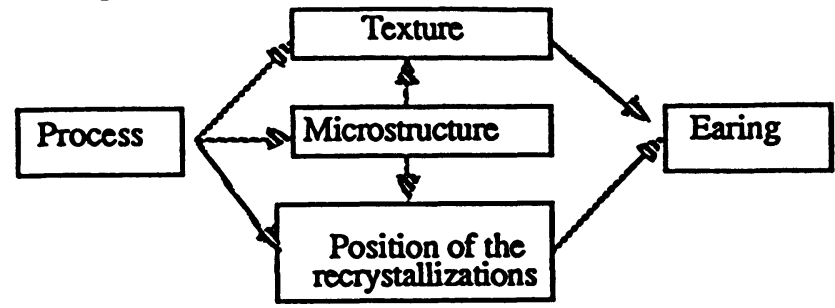


III-1 The Process/Texture/Earing relationship

The two elementary processes to be considered here are deformation and recrystallization.The evolution of earing along these two processes can be described by means of the earing diagram, which gives the earing percentage as a function of the rolling strain in the "H1X" (i.e. after deformation) and "O" (i.e. after deformation and annealing) tempers. $0 / 90^{\circ}$ (resp. $45^{\circ}$ ) earings are assumed to be represented by positive (resp. negative) values of $\mathrm{E} \%$.

An example of such an experimentally determined diagram is shown in Figure 2 for a C.P. alloy initially recrystallized. The linear variation of the H1X curve is commonly found in the literature [7].

The shape of the earing diagram is related to the evolution of texture through equations derived from Eq. (1):

$$
\mathrm{E}_{\mathrm{i}} \%(\varepsilon)=\mathrm{a}\left(2.7 \mathrm{C}_{\mathrm{i}}(\varepsilon)-\mathrm{R}_{\mathrm{i}}(\varepsilon)\right)
$$

where $\mathrm{i}=1$ (resp. 2 ) refers to the "H1X" (resp. "0") tempers. The experimentally determined texture evolutions are shown in Figure 3 for the C.P. alloy mentioned above. These can be modelled by phenomenological equations similar to those used by Andersson et al [4], i.e. :

$$
\begin{array}{ll}
\text { H1X Temper: } & \mathrm{C}_{1}(\varepsilon)=\mathrm{C}_{0} \exp (-\mathrm{k} \varepsilon) \\
& \mathrm{R}_{1}(\varepsilon)=\mathrm{R}_{0}+\mathrm{k}^{\prime} \varepsilon \\
\text { 0 Temper: } & \mathrm{C}_{2}(\varepsilon)=\mathrm{C}_{0}^{\prime} \exp \left(-\mathrm{k}^{\prime \prime} \varepsilon\right)+\mathrm{C}_{\mathrm{m}} \exp \left[\frac{1}{2}\left(\frac{\varepsilon-\varepsilon_{\mathrm{m}}}{\varepsilon_{0}}\right)^{2}\right] \\
& \mathrm{R}_{2}(\varepsilon)=\mathrm{R}_{0}+\mathrm{k}^{\prime \prime \prime} \varepsilon^{\mathrm{n}}
\end{array}
$$

The constants can be determined from the experimental curves of Figure 3. A combination of Eqs. 2 to 4 leads to the calculated earing diagram shown as dashed lines in Figure 2.

\section{III-2 The Microstructure / Texture Relationship}

Texture evolutions are strongly dependent on microstructural parameters such as solid solution content, distribution in size of second phase particles, grain size or dislocation density. The wavy curve of the earing diagram in the " $O$ " temper can be explained for example by the occurence of different mechanisms for the nucleation of recrystallization when stored energy is increased. As demonstrated by MAURICE et al [8] on a 3004 alloy, particle stimulated nucleation inducing a randomization of texture (and a low earing level) is prominent at low strains. At higher strains however, competing nucleation mechanisms involving second phase particles as well as transition bands lead to an increased intensity of the $R$ and Cube textures after recrystallization. Nucleation of the cube component along deformation bands has already been reported by NES et al [9]. It explains the high $0 / 90^{\circ}$ earing level measured in the annealed temper after large strains (see Figure 2). 
As long as the nucleation mechanisms involved during recrystallization highly depends on the microstructure of the sheet as well as on the deformation and annealing conditions, it is easily understood that the shape of the earing diagram in the " 0 " temper is not a constant for a given alloy.

On the other hand, it can be expected that the "H1X" curve is somewhat more independent of the microstructure than the " 0 " curve. Effect of grain size and initial texture on a delay of the texture development, as well as of large particles on a weakening of the texture has however been reported [10].

All these microstructural features may modify the set of constants used in Eqs 3 and 4, i.e. the shape of the earing curves, as shown schematically in Fig. 4.

\section{III-3 Some Insights in the Control of Earing}

Ear free material may be obtained at a given gauge by balancing the $45^{\circ}$ and $0 / 90^{\circ}$ earing tendencies. As rolling and annealing develop respectively $45^{\circ}$ and $0 / 90^{\circ}$ earing, it is clear that the complete fabrication schedule involving a series of deformation and recrystallization processes has to be controlled in order to realize the adequate texture balance. This can be done industrially by controlling the microstructure and the interpass recrystallizations on the hot-rolling line as well as by introducing interannealings in the cold rolling process. The concept of earing diagram described above can be used as a predictive tool for calculation of final earing as a function of fabrication schedule. This is simply done by assigning to the initial texture values (Co and Ro in Eq. 3 and 4) after each recrystallization process the $C 2$ and $R 2$ values corresponding to the preceding step.

An example of simulation realized in this way is shown in Figure 5 together with experimental measurements. It is seen that a control of the position of the recrystallizations on the hot-rolling line may lead to ear free material at different final gauges. As mentioned above, a modification of microstructure through a change in casting or pre-heating conditions may strongly modifies the texture evolution as well as the gauges at which recrystallization occurs. Final earing may be thus changed drastically.

\section{CONCLUSIONS}

Earing is one of the undesired effects of texture on metal sheet and must be kept at the lowest level as possible at the final gauge.

The production of ear free material may be realized by controlling the microstructural evolution during the complete fabrication schedule as well as the position of the recrystallizations during the hot-rolling and cold-rolling sequences. The concept of earing diagram coupled with a metallurgical simulation able to predict these events may be useful for this purpose.

\section{ACKNOWLEDGEMENTS}

The author is endebted to Pechiney Rhenalu for authorization to publish this paper. 


\section{REFERENCES}

1. K.D. Welson, B.L. Adams and W.G. Fricke, Proc. ICOTOM 8 Conf., 1987, Santa Fe, pp. 1097 - 1102.4.

2. B. Andersson and S.E. Naess, Proc. Conf. "Al Alloys - Physical and Mechanical Properties", Virginy, 1986, pp. 499 - 511.

3. G.E.C. Tucker, Acta Metall., 9, 1961, pp. 275 - 286.

4. N. Kanetake, Y. Tozawa and S. Yamamoto, Int. \& Mech. Sci., 27, 1985, pp. 249 256.

5. A. Pochettino, Thèse Doct. Ing., Univ. Orsay Paris-Sud, 1981.

6. P.M.B. Rodrigues and P.S. Bate, Proc. AIME Sump. on " Textures in non-ferrous metal and alloys" Detroit, 1984, pp. 173 - 188.

7. J.C. Blade, Proc. AIME Symp. on "Textures in non-ferrous metals and alloys", Detroit, 1984, pp. 1.

8. Cl. Maurice, J.H. Driver, G.M. Raynaud and Ph. Lequeu, this conference.

9. J. Hjelen, R. Ursund and E. Nes, submitted to

10. D. Juul Jensen, N. Hansen and F.J. Humphreys, Proc. ICOTOM 8 Conf. Santa Fe, 1987, pp. $431-444$.
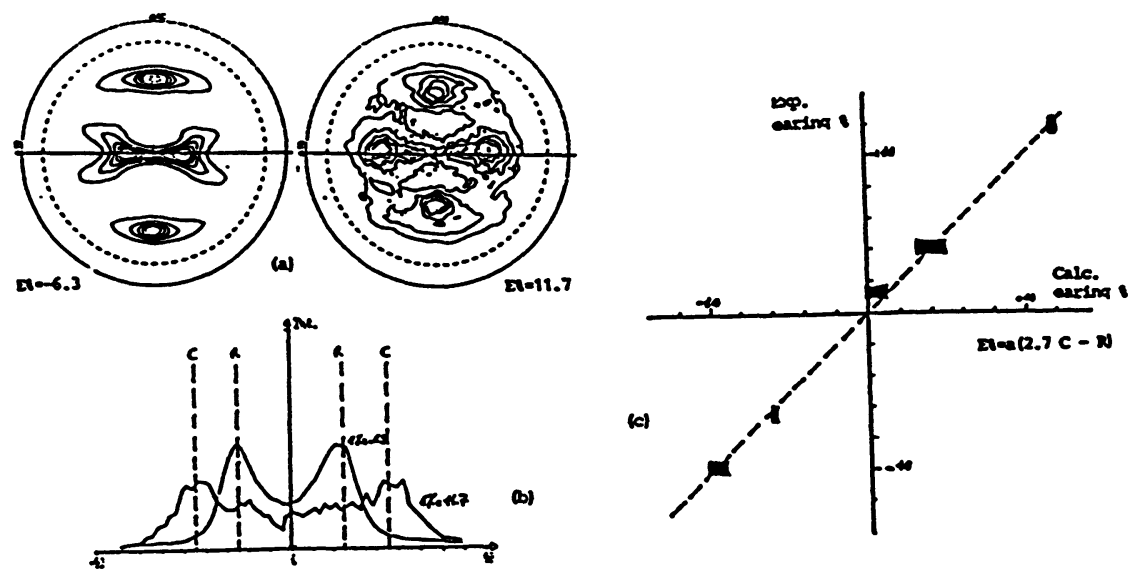

Figure 1 Determination of the texture / earing relationship - (a) (220) pole figures with corresponding earing percentage ; (b) corresponding sections in the (TD,ND) plane needed to determine the $R \& C$ intensities ; (c) experimental versus calculated $(E \%=a(2.7 C-R)$ ) . earing percentage for a range of C.P. alloys.

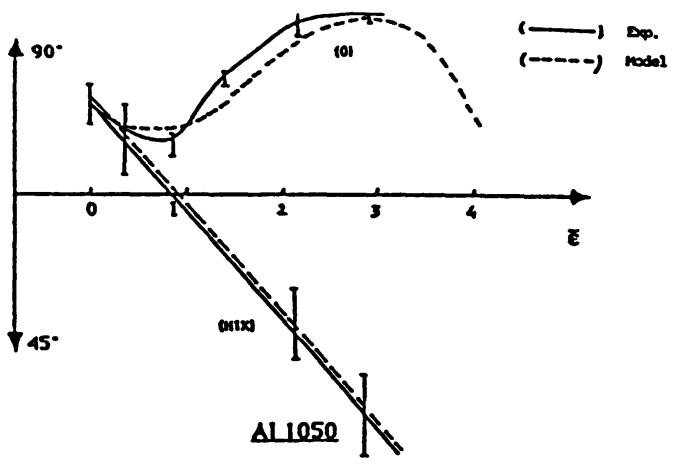

Figure 2

Experimental and calculated (Eqs 2 to 4) earing diagrams of a C.P. alloy initially recrystallized. 

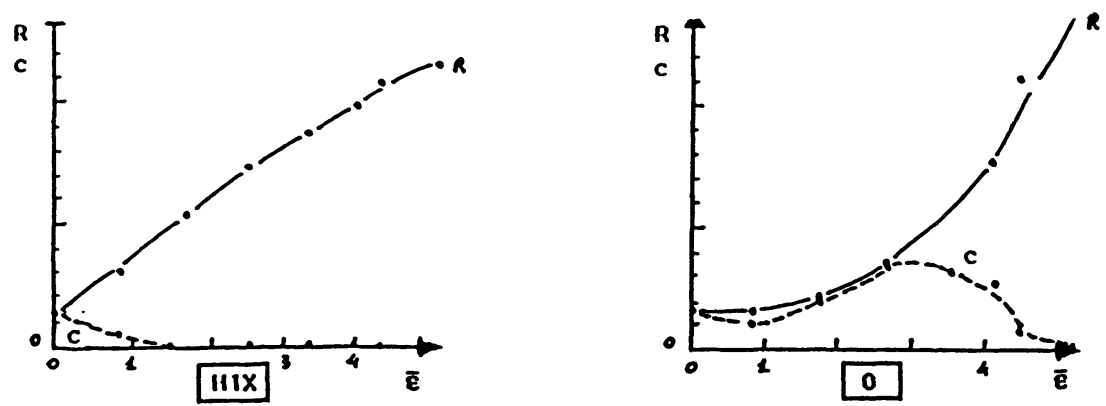

Figure 3 Evolution of the $\mathrm{R}$ and $\mathrm{C}$ texture components with equivalent strain in the H1X and $O$ tempers - C.P. Al

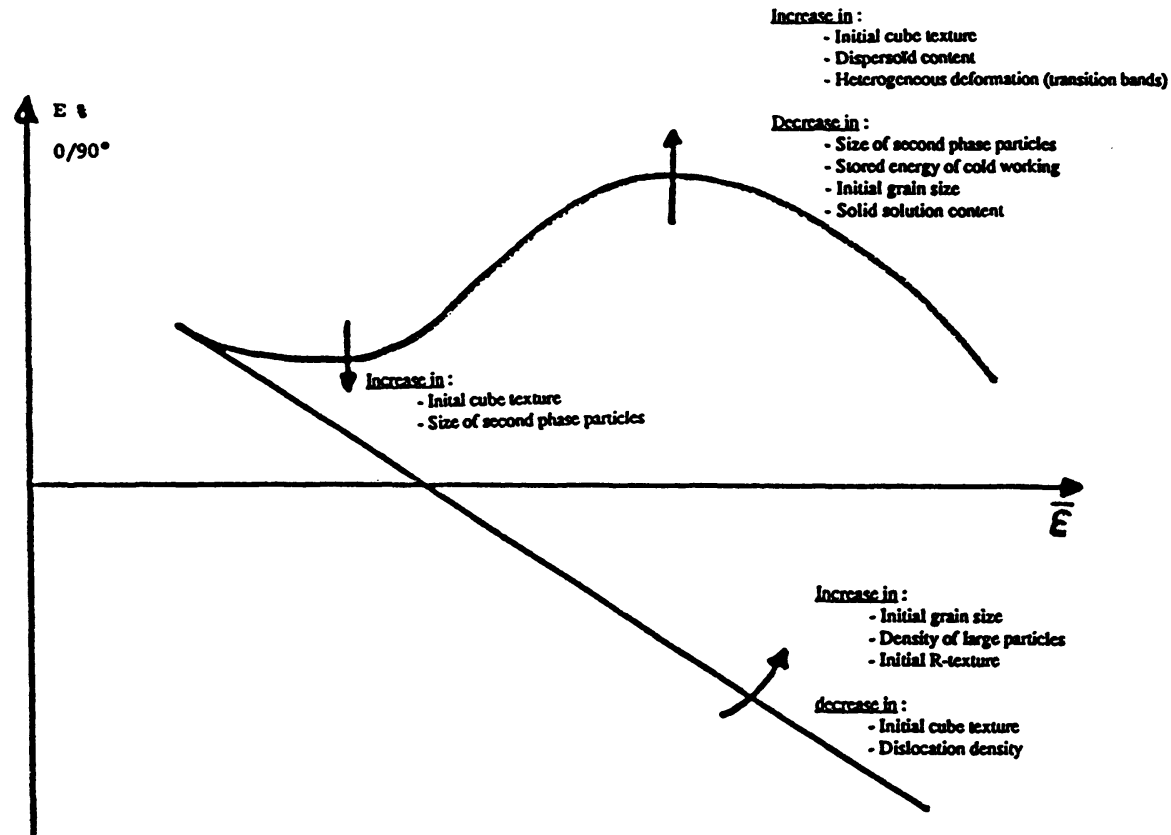

$45^{\circ}$

Figure 4 Schematic illustrating the influence of some metallurgical parameters on the shape of the earing diagram.

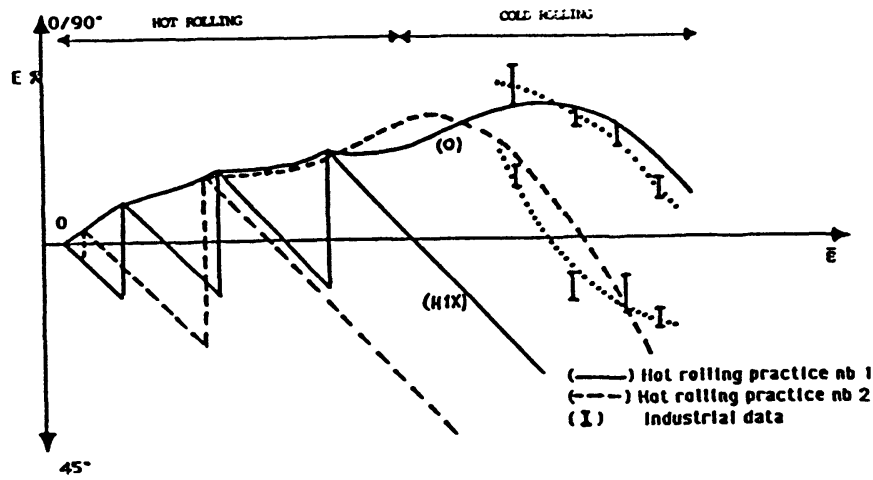

Figure 5

Influence of the hot rolling practice of a commercial purity aluminium on the final earing of the annealed condition 